\title{
DESIGNING FOR DIVERSITY: INCLUSIVE SAMPLING
}

\author{
Rod D. Roscoe, Ph.D. \\ rod.roscoe@asu.edu and http://orcid.org/0000-0001-8327-4012
}

Human Systems Engineering, Arizona State University, Mesa, Arizona, United States

research methods, sampling, inclusion, equity

Experts in human factors and ergonomics $(H F / E)$ and related fields have the ability and responsibility to broadly serve the needs and goals of diverse people, which encompasses issues of inclusion, equity, and justice. Importantly, HF/E designers, researchers, and practitioners can address these aims both as the intended outcomes of their work and how the work itself is conducted. Both pathways support progress toward more inclusive and equitable organizations and societies. This paper focuses upon one aspect of inclusive methodology-strategies for inclusive sampling. Sampling is an important focus because of its fundamental role in defining the internal and external validity of findings. Moreover, sampling is how diverse participants and perspectives are incorporated (or not), and thus represents an early way that exclusion, inequity, or inaccessibility may manifest. Three heuristic questions and six sets of strategies are briefly articulated: (1) purposive sampling, (2) oversampling, (3) community sampling, (4) removing barriers of distance, cost, communication, and awareness, (5) building trust, and (6) inclusive demographic categories. A variety of sources are cited to facilitate readers' further consideration of these issues in their own HF/E endeavors.

Received in: 12 / $11 / 2020$

Accepted in: $20 / 06 / 2021$

DOI: http://dx.doi.org/10.22570/ergodesignhci.v9i1.1502 


\section{Introduction}

Human factors and ergonomics (HF/E) and related fields emphasize the centrality of human needs, goals, capabilities, and constraints in the design of systems that will work for people (Roscoe et al., 2019). Importantly these concerns encompass how people are included or excluded, and how they are empowered or oppressed. People need to experience meaningful autonomy and agency in their daily lives (Slemp, Kern, Patrick, \& Ryan, 2018; Van den Broeck, Ferris, Chang, \& Rosen, 2016). Systems of exclusion and oppression hinder people achieving their full potential and their overall well-being (Lui \& Quezada, 2019; Schmitt, Bransombe, Postmes, \& Garcia, 2014), such as in workplace and organizational settings (Dhanani, Beus, \& Joseph, 2017; Jones, Arena, Nittrouer, Alonso, \& Lindsey, 2017; Robinson, O'Reilly, \& Wang, 2013). Consequently, HF/E has a crucial responsibility and opportunity to advocate for equity, inclusion, and justice (Chiou \& Roscoe, 2021; Roscoe, Chiou, \& Wooldridge, 2020).

Fortunately, there are multiple paths that HF/E experts can follow to support greater inclusion and equity. As depicted in Figure 1, these routes comprise both HF/E goals (i.e., what people seek to achieve) along with HF/E practices (i.e., how people do the work) (Chiou \& Roscoe, 2021).

\section{Inclusion and Equity}

- organizations and societies that are fair, accessible, and welcoming

- reduce experiences of discrimination and oppression for all people

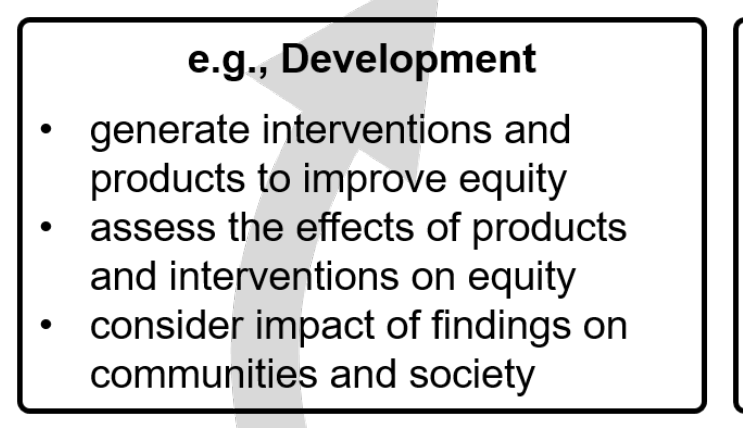

e.g., Understanding

- demonstrate patterns or effects of exclusion and inequity

- explain associations and causes that produce inequity

\section{e.g., Data}

- recruit inclusive, equitable, and representative samples

- consider more nuanced demographic characteristics

- use analytical frameworks that address intersectionality

\section{e.g., Teams}

- involve diverse stakeholders, members, and perspectives

- employ participatory methods throughout the process

\begin{tabular}{c|c|}
\hline HF/E Goals & HF/E Practices \\
purposes and products & methods and tools \\
\hline Human Factors and Ergonomics (HF/E) \\
foundational theories and principles
\end{tabular}

Figure 1. Pathways toward inclusion and equity for human factors and ergonomics.

First, designers, researchers, and practitioners can seek to understand critical patterns and variables related to inclusion and equity. For instance, Benda and Bisantz (2019) have shared cases in which work domain analysis (WDA) revealed social justice issues related to housing and for patient communication in emergency departments. WDA models helped investigators conceptualize complex housing and medical 
systems and study how those environments were driven by human goals and decision-making. In turn, the resulting models allowed designers to understand how decisions and disruptions propagated through the system. Strategic interventions (e.g., new tools to supplement professional interpreters in emergency rooms) could be proposed to encourage more equitable processes. Similarly, Rodriguez and Gaviria (2019) demonstrated how ergonomic analyses could reveal the experiences, needs, and challenges of recycler communities. Their work shed light on the interplay of individual characteristics (e.g., age and education), task demands, environments, organizations, technology, safety, and psychosocial factors that contributed to the well-being or harm for recyclers (e.g., inadequate personal protective equipment despite regulations).

The intersections of human factors, health equity, and social determinants of health are likewise increasingly important topics (Holden, Toscos, \& Daley, 2019; Wesley, Boxley, Kurgatt, King, \& Miller, 2019). A recent edited volume on patient ergnomics (Valdez \& Holden, 2021) devoted an entire section and multiple chapters to special concerns for healthcare and design for veterans, children, older adults, and underserved populations. Such research empowered designers to recognize exclusion and marginalization, and to understand their harmful effects on human performance and well-being. Such work enables experts to develop possible solutions (e.g., technologies for older adults, Harris, Nie, \& Rogers, 2019) and evaluate these tools for efficacy. In sum, HF/E experts can address equity and inclusion as the direct focus and desired outcomes of their work.

Second, inclusion and equity can also be infused into how people work - their methods and approaches. $\mathrm{HF} / \mathrm{E}$ experts can strive to inclusively and equitably build teams and partnerships, collect and analyze data, and interpret findings and impact. Research has shown that authentic diversity can benefit creativity and innovation in teams (Salazar, Feitosa, \& Salas, 2017; Salazar, Lant, Fiore, \& Salas, 2012). When teams are demographically and intellectually diverse, they may be more prepared to generate and evaluate a broader range of ideas. Importantly, these benefits depend on teams sharing a salient team identity while also integrating the identities and contributions of individual team members.

In data analyses, intersectional approaches can explore nuanced effects of demographic variables (Bowleg, 2008; Else-Quest \& Hyde, 2016a, 2016b). People define themselves in many ways and along diverse dimensions (e.g., race, ethnicity, gender, sexuality, ability, religion, and occupation). These various identities overlap and intersect, often with implications for inequity, discrimination, and oppression. Awareness of these issues allows people to develop more nuanced models, interpretations, and explanations of research findings. For example, understanding the needs and challenges of older adults (e.g., active aging, mattering, and neglect; Harris et al., 2019) can help to explain technology design and adoption beyond basic usability principles. Power dynamics and oppression also affect how and whether people participate in research, interact with researchers, and interpret and perform research tasks. For psychological scientists, Cole (2009) proposed three useful heuristic questions for thinking about social categories of participants and populations: "Who is included within this category?" "What role does inequality play?" "Where are there similarities?" These questions can be applied throughout all stages of research to offer an intersectional way of thinking about hypothesis generation, sampling, operationalization, analysis, and interpretation.

Similarly, when assessing impact, experts can think beyond scientific impact (e.g., citation counts) to appreciate societal impact on economic trends, government policy, and public attitudes (Bornmann, Haunschild, \& Adams, 2019; Ozanne et al., 2017; Rogers et al., 2020; Roscoe et al., 2020). HF/E scholars and practitioners can redefine the scope of their work in terms of solving meaningful social and societal problems and developing more equitable and inclusive systems, such as fairer elections, food and water security, sustainability, mental health care, and reducing social isolation (Rogers et al., 2020). Another important element of attaining societal impact is communicating such contributions to the broader public via education, outreach, and the news media (Roscoe et al., 2020). 
This paper focuses attention on one specific aspect of inclusive research and design. Specifically, this work addresses sampling - who we are studying and how they are recruited. Sampling is an important focus because of its fundamental role in defining the internal and external validity of findings. Moreover, sampling is how diverse participants and perspectives are incorporated (or not), and thus represents an early way that exclusion, inequity, or inaccessibility might manifest. The remainder of this paper briefly discusses the importance of representative sampling, threats to inclusive sampling, and strategies for inclusive sampling.

\section{Sampling and Exclusion}

As taught in numerous sources, sampling refers to procedures for identifying and recruiting participants as sources of data (e.g., Levy \& Lemeshow, 2013; Shadish, Cook, \& Campbell, 2002). Although researchers and designers often aim to draw conclusions or develop products that are meaningful across a range of people and contexts (e.g., working, learning, and playing), it is rarely possible to measure the entire population of interest. Just as doctors draw blood samples to evaluate signs of health, and ecologists draw water samples to evaluate levels of pollution in rivers, $\mathrm{HF} / \mathrm{E}$ experts gather data from samples of people to make inferences about how others think, feel, and behave.

A fundamental principle of effective sampling is that the samples must be representative (Corrigan \& Onwuegbuzie, 2020; Onwuegbuzie \& Collins, 2007; Shadish et al., 2002). The samples must demonstrate a comparable composition and range of characteristics to the group(s) of interest. Valid inferences can only be generated for groups similar to the sample. This is true for any data gathering effort, whether for formal hypothesis testing, user testing, decision making, or design. Sampling that is too demographically skewed or exclusionary can only produce results that are skewed, incomplete, and/or biased.

In the popular book, Invisible Women: Data Bias in a World Designed for Men, Perez (2019) documents numerous examples of systems and products that were designed without sufficient attention to sex and gender variation. Specifically, she argued that men are often implicitly viewed as "the human default," with diverse and adverse effects on women's experiences with medicine (e.g., diagnosis and treatment), safety (e.g., automobile crash tests and chemical exposure), and everyday products (e.g., smart phones). Similar demographic exclusions and neglect contribute to broad inequities in technology design (Wachter-Boettcher, 2017) and algorithms that shape information-seeking, decision-making, and technology (Noble, 2018).

Most HF/E experts probably do not intend to recruit biased or exclusionary samples. However, a substantial amount of work in the social sciences relies on recruiting people who are nearby, ready, willing, and able to participate. When working in academic settings, researchers often rely on university "subject pools" or "participant pools" (e.g., students in undergraduate classes who participate in studies for course credit) (Gallander Wintre, North, \& Sugar, 2001; Rocchi, Beaudry, Anderson, \& Pelletier, 2016; Walker, 2020). In work with consumers, one might recruit customers shopping in nearby businesses. Similarly, in industry settings, one might test designs among coworkers. Collectively, these approaches all represent forms of convenience sampling.

A number of scholars have adopted the acronym "WEIRD" to characterize systematically skewed sampling in the social sciences (particularly in the United States) (Bergman \& Jean, 2016; Clancy \& Davis, 2019; Henrich, Heine, \& Norenzayan, 2010; Nielsen, Haun, Kärtner, \& Legare, 2017). WEIRD stands for "Western," "educated," "industrialized," "rich," and "democratic." In brief, research reviews have revealed that participants are frequently recruited from cultures, communities, and organizations defined by certain economic and societal principles (e.g., capitalism and meritocracy), higher levels of education, and higher income. These trends are partly driven by reliance on recruiting university students as participants (i.e., confounded with education and income) and participants who have the time and mobility to enroll in studies. As a result of WEIRD sampling, research and practice in the social sciences may systematically exclude 
marginalized and minority communities, exclude persons from different socioeconomic backgrounds, exclude persons with disabilities, exclude persons living in rural areas, and more.

The consequences of such exclusions have been documented in growing library of well-articulated and popular resources (e.g., Anthony, 2017; Costanza-Chock, 2020; Hendren, 2020; Holmes, 2020; Noble, 2018; O’Neil, 2017; Perez, 2019; Wachter-Boettcher, 2017).

In sum, based on the importance of inclusive and representative samples for valid HF/E work, it is worthwhile to consider inclusive sampling strategies. What can HF/E experts do to ensure their participants embody meaningful diversity, particularly for people often ignored, neglected, or disenfranchised? A handful of recommendations are articulated below.

\section{Inclusive Sampling Strategies}

Systematic constraints on participant availability result in systematic exclusions that restrict validity and generalizability. Numerous factors can hinder inclusive sampling (Clark et al., 2019; Ford et al., 2007; George, Duran, \& Norris, 2014; Heller et al., 2014; Waheed, Hughes-Morley, Woodham, Allen, \& Bower, 2015). Taking inspiration from Cole (2009), these considerations can be broadly framed as heuristic questions for $\mathrm{HF} / \mathrm{E}$ experts to ask when designing experiments, focus groups, interviews, and other data collection efforts:

- Who is not present to participate in the study? For instance, if recruitment takes place among students, customers, or coworkers, then one must consider who is not enrolled in those schools, not shopping at those stores, or not employed in those companies. Schools that are located in affluent neighborhoods will offer little access to students affected by poverty. Stores that are located within densely-populated urban settings will host different consumers than suburban or rural regions. Researchers must also consider how populations may change over time (e.g., throughout the work day or seasonally) and how that affects who is present and available to participate.

- What logistical barriers prevent people from participating in the study? People cannot participate when they lack the time, transportation, or technology to access the research materials or data collection sites, whether physically or virtually. Importantly, such resources are not equitably distributed throughout the broader population. Thus, logistical constraints result in systematic exclusion of individuals who are already under-resourced and under-served.

- Who chooses not to participate in the study? Some individuals or communities may possess justifiable distrust toward researchers and designers, perhaps due to concerns about privacy, fear of exploitation or data misuse, or previous negative experiences.

$\mathrm{HF} / \mathrm{E}$ experts can employ a variety of approaches to overcome these challenges. Importantly, these strategies are not intended to be exhaustive, but may help people "get started" or inspire further innovation.

\subsection{Strategy 1: Purposive Sampling}

In contrast to convenience sampling, purposive sampling involves intentional recruitment of participants from specific populations or groups of people (Gentles, Charles, Ploeg, \& McKibbon, 2015; Levy \& Lemeshow, 2013; Palinkas et al., 2015; Patton, 2015). Instead of relying on chance to include diverse people, researchers can determine necessary populations in advance and strategically recruit them. Specifically, designers can review their prior work to assess who has been omitted. If participant demographics were 
skewed with respect to race, gender, ability status, language, or other factors, future recruitment can directly address these gaps. Researchers can reach out to new organizations or networks who were not previously invited. Stratified and quota sampling can increase accountability by defining who needs to be recruited, how many people, and from which underrepresented groups, for a study to be considered "complete."

\subsection{Strategy 2: Oversampling}

A related approach is oversampling to ensure larger or statistically adequate sample sizes of "rare" populations (Hauner, Zinbarg, \& Revelle, 2014; Kalton, 2009). By definition, "minority" groups possess fewer members relative to the broader population. Thus, a sample might be proportionally representative (i.e., the demographic composition of the sample is comparable to the population) yet still unable to support meaningful comparisons or conclusions about a given demographic. For example, some estimates report that transgender individuals comprise less than $1 \%$ of adults (e.g., Flores, Brown, \& Herman, 2016; Zhang et al., 2020). Thus, a proportionally representative sample of 100 people might include 1 to 2 transgender individuals; a sample of 1000 might include 10 transgender individuals, and so on. The subset of transgender participants would be substantially underpowered for many analyses. Purposive oversampling strives to recruit sample sizes that enable meaningful conclusions about people regardless of minority status.

\subsection{Strategy 3: Community Sampling}

A parallel approach to purposive sampling is community sampling, which involves recruiting people within broader communities defined by shared culture, identity, history, geography, or purpose (Constanza-Chock, 2020, Israel, Eng, Schulz, \& Parker, 2013; Jason \& Glenwick, 2016; Palinkas et al., 2015; Valerio et al., 2016). All organizations are constrained - such as university entrance requirements and tuition fees, or corporate employment qualifications and hiring policies - which inherently restricts the range of people associated with those organizations. Recruiting from local communities begins to bypass those filters.

Community sampling aligns well with community-based research practices (Benda et al., 2020; ConstanzaChock, 2020). HF/E experts can intentionally strive to work with under-served communities most affected by inequity (e.g., Valerio et al., 2016; Waheed et al., 2015; Wallerstein \& Duran, 2010). Community members can be instrumental in identifying and defining problems, establishing research questions, selecting methods, analyzing data, and interpreting the results. This approach can restore agency and power to marginalized groups who are normally excluded from these decisions and procedures. In such cases, the outcome is not only more inclusive sampling, but perhaps also justice for the communities (e.g., Wallerstein, Duran, Oetzel, \& Minkler, 2018).

\subsection{Strategy 4: Remove Barriers to Participation}

Despite best intentions to recruit from diverse populations and communities, logistical and psychosocial barriers can hinder inclusion (Benda et al., 2020; George et al., 2014; Sheridan et al., 2020; Stonewall et al.., 2019). A third strategy (or set of strategies) is to enable participation -identify factors that limit participation in data collection and then remove those barriers.

- Strategy 4a: Reduce the demands of physical distance. Some participants may lack the time or transportation to visit the research site. Overcoming this obstacle may require establishing new locations closer to communities or ensuring that sites are accessible via public transportation. Another method is to employ tools for virtual or electronic data collection, such as remote meetings, 
chat messaging, digital diaries, or web-based surveys. These approaches require reliable Internet access but negate the need for travel.

- Strategy 4b: Reduce financial constraints. HF/E experts should be mindful that taking part in a study may require time away from work, childcare expenses, travel expenses, or other costs. People with fewer financial resources may find it impossible or unjustifiable to participate. Researchers might address this problem by scheduling data collection outside of work hours, but this may conflict with time for household chores, family, or recreation. An alternative approach is to provide meaningful financial compensation that accounts for (or exceeds) the costs of participating. Any required technologies (e.g., a mobile device) should be also made available to at no cost.

- Strategy 4c: Improve and enable communication. The preferred language of the HF/E team may not be shared by participants. Individuals who lack fluency in reading research materials (e.g., advertisements, consent forms, and instructions), writing responses, or speaking with the researchers (e.g., in focus groups) may thus be excluded. These concerns can be addressed by working with translators or interpreters who can facilitate communication across language barriers. All materials should appear in languages relevant to the target populations, and participants should have the ability to express themselves in their own language.

- Strategy 4d: Raise awareness and be inviting. Diverse individuals and communities may not have equivalent access to learning about research opportunities. Flyers placed on university bulletin boards, office break rooms, or on social media can only be seen by people who visit those spaces. $\mathrm{HF} / \mathrm{E}$ experts should advertise broadly in diverse venues and learn how target communities typically communicate (e.g., signage or word-of-mouth). Advertisements must also be welcoming — not just an "announcement" of a study, but a clear invitation and encouragement to take part. Recruitment materials should clearly communicate that peoples' time and contributions will be valued.

\subsection{Strategy 5: Build Participant Trust and Confidence}

Some individuals and communities choose not to participate in data collection because they are justifiably wary of research, researcher motives, and ethics (Christopher, Watts, Knows His Gun-McCormick, \& Young, 2008; Frerichs et al., 2018; Waheed et al., 2015; Williams \& Gilbert, 2019; Wood, 2017).

Differences in resources (e.g., funding), perceived prestige (e.g., corporate and university credentials), and other factors also give rise to power imbalances between researchers and communities. Participants may feel they have little control over how they participate in the study, worry about how their data will be used or interpreted, or even fear for their safety. For instance, Williams and Gilbert (2019) documented how research with neuroatypical or disabled individuals can be dominated by "proxies" (e.g., parents or other caregivers) who speak on behalf of the participants, resulting in a loss of voice, agency, and trust. As a result, findings or designs are oriented toward the needs or goals of the proxy rather than the participants, and participants feel powerless, ignored, or objectified.

To alleviate these valid concerns, HF/E experts should be transparent about project goals, methods, precautions, expectations, and outcomes. In addition, participants (and their communities), should have a substantive voice in the project - as partners, co-researchers, co-designers, and co-evaluators (ConstanzaChock, 2020; Wallerstein et al., 2018). Their needs, expertise, insights, and culture should have influence on project design and decisions (Berryman, Soohoo, \& Nevin, 2013). HF/E experts should also consider how their "research goals" or "design problems" align to the target community or population. Through such authentic partnerships and collaborations, the inner workings of the research are made visible and interactive rather than mysterious or suspicious. Findings and products should also benefit people and communities in both the short-term and long-term and should never contribute to continued inequity. Trust is established and 
reinforced when the benefit of the work is meaningful and tangible, the potential for harm is reduced, and participants have the power to define what constitutes "benefit" or "harm."

\subsection{Strategy 6: Inclusive Demographic Categories}

A final strategy pertains to how participants are characterized during recruitment and analysis. People identify themselves using a wide variety of dimensions, categories, and labels (e.g., gender, sexuality, ethnicity, race, ability, occupation, and religion). These categories combine and intersect with significant ramifications for inequity, discrimination, and oppression (Bowleg, 2008; Cole, 2009; Collins, 2015; ElseQuest \& Hyde, 2016a, 2016b). If these nuances are not respected during recruitment and analysis, then efforts to be inclusive will be undermined. Participants are essentially made "invisible" when they cannot identify themselves accurately and as they prefer.

Researchers should avoid limited and restrictive category labels (e.g., only binary "Female" or "Male" options) and people should be able to describe multiple facets of their race and ethnicity without conflating the two. A common best practice is to provide multiple categories for race and instruct participants to "select all that apply." Care should also be taken to avoid labels that make people feel unwelcome or invisible (e.g., "Other" or "non-White"). When writing about different communities, researchers should respect preferences for person-first versus identity-first language (Dunn \& Andrews, 2015; Gernsbacher, 2017). Person-first language strives to elevate personhood and reduce bias by not defining people by or as a disability (e.g., "person with schizophrenia" instead of "schizophrenic"). However, identify-first language highlights salient characteristics that people embrace as normal and integral to their self - such as Autistic or Deaf and Hard of Hearing - and challenges conceptualizations of what is considered a "disability." Because different communities may prefer use of person-first or identity-first language, it is essential to work with people to understand and respect their preferences. Finally, people should also have the option to not disclose their identity (e.g., "Prefer Not to Say"). Ultimately, if people cannot accurately, positively, and safely identify themselves, then it is difficult to feel authentically included.

Similarly, during analysis, it may be crucial to explore whether demographic differences influence findings, design decisions, or impact. However, these analyses are only possible when nuanced and inclusive categories can be represented in the data (Else-Quest \& Hyde, 2016b). It is impossible to determine whether a sample is representative if the sample cannot be properly characterized. And, if HF/E experts fail to collect these data, then they lose the ability to detect or be responsive to the needs of diverse groups (Chiou \& Roscoe, 2021).

\section{Conclusion}

Human factors and ergonomics (HF/E) and related fields have the ability and responsibility to broadly serve human needs and goals, which encompasses issues of inclusion, equity, and justice. HF/E experts can seek to reveal inequities, understand the complex causes and systems of disparities, and develop technologies or other interventions to reduce these injustices. HF/E experts can also embrace more inclusive and equitable practices for assembling research and design teams, collecting and analyzing data, and conceptualizing their findings and impact. In sum, HF/E can address inclusion and equity both through the intended outcomes of the work and how the work itself is conducted — both pathways support progress toward more inclusive and equitable organizations and societies.

This paper focused upon one aspect of inclusive methodology — strategies for sampling. Three heuristic questions and six sets of strategies were provided (summarized in Figure 2). This work highlighted sampling because of its essential and early role in establishing the validity and generalizability of our outcomes, yet other methodological concerns (e.g., study designs, elicitation and observation protocols, and analytical 
frameworks) are just as important. HF/E experts are encouraged to think deeply, expansively, and creatively about the inclusion and equity ramifications of all methods.

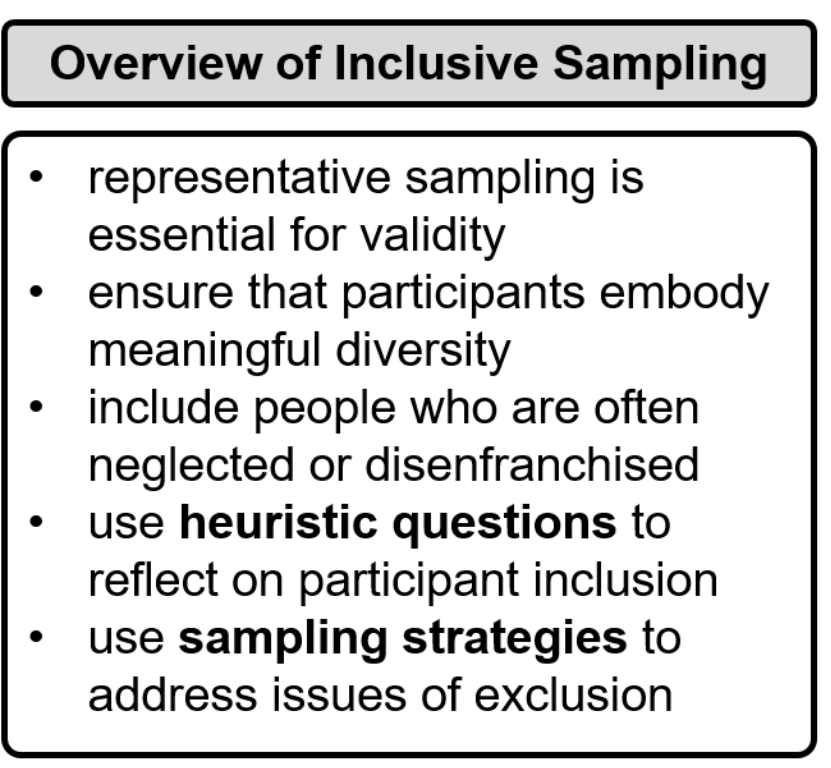

\section{Three Heuristic Questions}

\section{Who is not present?}

- location and time can influence who is present and available

\section{What prevents participation?}

- lack of time, transportation, or technology limit participation

- inequitable resource access

\section{Who chooses not to participate?}

- distrust; fears about privacy, safety, or exploitation

- lack of agency or voice

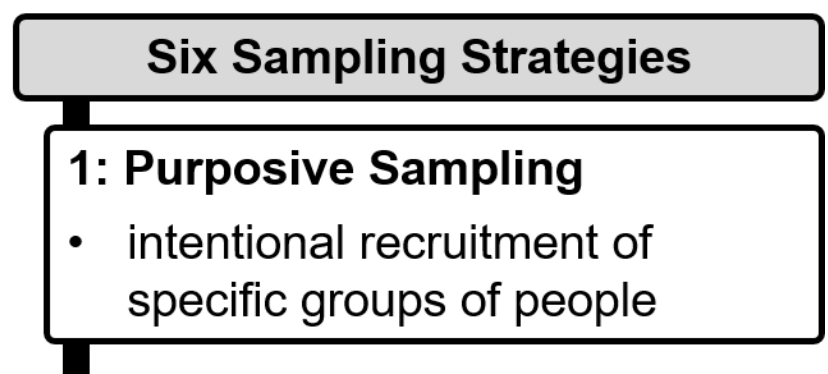

2: Oversampling

- recruit larger numbers of "rare" populations for valid analysis

\section{3: Community Sampling}

- recruit and collaborate with community members

\section{4: Remove Barriers}

- reduce demands of distance

- reduce financial constraints

- enable communication

- raise awareness; be inviting

\section{5: Build Trust}

- consider power; transparency

- align with community goals

\section{6: Inclusive Demographics}

- allow people to self-identify accurately and as they prefer

Figure 2. Summary of heuristic questions and strategies for inclusive sampling.

\section{References}

Anthony, K. H. (2017). Defined by design: The surprising power of hidden gender, age, and body bias in everyday products and places. Amherst, NY: Prometheus Books. 
Benda, N. C., \& Bisantz, A. M. (2019). Using work domain analysis to advocate for social justice. In R. D. Roscoe, E. K. Chiou, \& A. R. Wooldridge (Eds.), Advancing diversity, inclusion, and social justice through human systems engineering (pp. 79-102). Boca Raton, FL: CRC Press. https://doi.org/10.1080/00140139.2020.1818431

Benda, N. C., Montague, E., and Valdez, R. S. (2020). Design for inclusivity. In A. Sethumadhavan \& F. Sasangohar (Eds.), Design for health: Applications of human factors. Cambridge, MA: Academic Press. https://doi.org/10.1016/C2018-0-00043-2

Bergman, M. E., \& Jean, V. A. (2016). Where have all the "workers" gone? A critical analysis of the unrepresentativeness of our samples relative to the labor market in the industrial-organizational psychology literature. Industrial and Organizational Psychology, 9(1), 84-113. https://doi.org/10.1017/iop.2015.70

Bornmann, L., Haunschild, R., \& Adams, J. (2019). Do altmetrics assess societal impact in a comparable way to case studies? An empirical test of the convergent validity of altmetrics based on data from the UK Research Excellence Framework (REF). Journal of Infometrics, 13(1), 325-340.

https://doi.org/10.1016/j.joi.2019.01.008

Bowleg, L. (2008). When Black + lesbian + woman $\neq$ Black lesbian woman: The methodological challenges of qualitative and quantitative intersectionality research. Sex Roles, 59, 312-325.

https://doi.org/10.1007/s11199-008-9400-z

Chiou, E. K., \& Roscoe, R. D. (2021). Assessing authentic diversity in the Human Factors and Ergonomics Society: Part 2. Ergonomics in Design. https://doi.org/10.1177/10648046211015751

Christopher, S., Watts, V., Knows His Gun McCormick, A., \& Young, S. (2008). Building and maintaining trust in a community-based participatory research partnership. American Journal of Public Health, 98(8), 1398-1406. https://doi.org/10.2105/AJPH.2007.125757

Clancy, K. B. H., \& Davis, J. L. (2019). Soylent is people, and WEIRD is White: Biological anthropology, Whiteness, and the limits of the WEIRD. Annual Review of Anthropology, 48, 169-186. https://doi.org/10.1146/annurev-anthro-102218-011133

Clark, L. T., Watkins, L., Pina, I. L., Elmer, M., Akinboboye, O., Gorham, M., \& ..., Regnante, J. M. (2019). Increasing diversity in clinical trials: Overcoming critical barriers. Current Problems in Cardiology, 44, 148172. https://doi.org/10.1016/j.cpcardiol.2018.11.002

Collins, P. H. (2015). Intersectionality's definitional dilemmas. Annual Review of Sociology, 41, 1-20.

https://doi.org/10.1146/annurev-soc-073014-112142

Corrigan, J. A., \& Onwuegbuzie, A. J. (2020). Toward a meta-framework for conducting mixed methods representation analyses to optimize meta-inferences. The Qualitative Report, 25(3), 785-812.

Costanza-Chock, S. (2020). Design justice: Community-led practices to build the worlds we need. Cambridge, MA: MIT Press. https://doi.org/10.7551/mitpress/12255.001.0001

Dhanani, L. Y., Beus, J. M., \& Joseph, D. L. (2017). Workplace discrimination: A meta-analytic extension, critique, and future research agenda. Personnel Psychology, 71(2), 147-179.

https://doi.org/10.1111/peps.12254

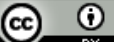


Dunn, D. S., \& Andrews, E. E. (2015). Person-first and identity-first language: Developing psychologists' cultural competence using disability language. American Psychologist, 70(3), 255-264.

https://doi.org/10.1037/a0038636

Else-Quest, N. M., \& Hyde, J. S. (2016a). Intersectionality in quantitative psychological research: I. Theoretical and epistemological issues. Psychology of Women Quarterly, 40(2), 155-170. https://doi.org/10.1177/0361684316629797

Else-Quest, N. M., \& Hyde, J. S. (2016b). Intersectionality in quantitative psychological research: II. Methods and techniques. Psychology of Women Quarterly, 40(3), 319-336.

https://doi.org/10.1177/0361684316647953

Flores, A. R., Brown, T. N. T., \& Herman, J. L. (2016). Race and ethnicity of adults who identify as transgender in the United States. Los Angeles, CA: The Williams Institute, UCLA School of Law.

Frerichs, L., Kim, M., Dave, G., Cheney, A., Lich, K., Jones, J., \& ... Corbie-Smith, G. (2018). Stakeholder perspectives on creating and maintaining trust in community-academic research partnerships. Health Education \& Behavior, 44(1), 182-191. https://dx.doi.org/10.1177\%2F1090198116648291

Ford, J. G., Howerton, M. W., Lai, G. Y., Gary, T. L., Bolen, S., Gibbons, M. C., .. Bass, E. B. (2007). Barriers to recruiting underrepresented populations to cancer clinical trials: A systematic review. Cancer, 112(2), 228-242. https://doi.org/10.1002/cncr.23157

Gallander Wintre, M., North, C., \& Sugar, L. A. (2001). Psychologists' response to criticisms about research based on undergraduate participants: A developmental perspective. Canadian Psychology/Psychologie Canadienne, 42(3), 216-225. https://doi.org/10.1037/h0086893

Gentles, S. J., Charles, C., Ploeg, J., \& McKibbon, K. (2015). Sampling in qualitative research: Insights from an overview of the methods literature. The Qualitative Report, 20(11), 1772-1789. Retrieved from https://nsuworks.nova.edu/tqr/vol20/iss11/5

George, S., Duran, N., \& Norris, K. (2014). A systematic review of barriers and facilitators to minority research participation among African Americans, Latinos, Asian Americans, and Pacific Islanders. American Journal of Public Health, 104(2), e16-31. https://doi.org/10.2105/AJPH.2013.301706

Gernsbacher, M. A. (2017). Editorial perspective: The use of person-first language in scholarly writing may accentuate stigma. Journal of Child Psychology and Psychiatry, 58(7), 859-861.

https://doi.org/10.1111/jepp.12706

Henrich, J., Heine, S. J., \& Norenzayan, A. (2010). The weirdest people in the world? Behavioral and Brain Sciences, 33, 61-83. https://doi.org/10.1017/S0140525X0999152X

Harris, M. T., Nie, Q., \& Rogers, W. A. (2019). Guiding technology design to empower older adults to actively engage in society. In R. D. Roscoe, E. K. Chiou, \& A. R. Wooldridge (Eds.), Advancing diversity, inclusion, and social justice through human systems engineering (pp. 151-170). Boca Raton, FL: CRC Press. https://doi.org/10.1080/00140139.2020.1818431

Heller, C., Balls-Berry, J. E., Nery, J. D., Erwin, P. J., Littleton, D., Kim, M., \& Kuo, W. P. (2014). Strategies addressing barriers to clinical trial enrollment of underrepresented populations: A systemic review. Contemporary Clinical Trials, 39(2), 169-182. https://doi.org/doi:10.1016/j.cct.2014.08.004 
Hendren, S. (2020). What can a body do? How we meet the build world. New York, NY: Riverhead Books.

Holden, R. J., Toscos, T., \& Daley, C. N. (2019). Research reflections on human factors and health equity. In R. D. Roscoe, E. K. Chiou, \& A. R. Wooldridge (Eds.), Advancing diversity, inclusion, and social justice through human systems engineering (pp. 51-62). Boca Raton, FL: CRC Press.

https://doi.org/10.1080/00140139.2020.1818431

Holmes, K. (2020). Mismatch: How inclusion shapes design. Cambridge, MA: MIT Press. https://doi.org/10.7551/mitpress/11647.001.0001

Hauner, K. K., Zinbarg, R. E., \& Revelle, W. (2014). A latent variable model approach to estimating systematic bias in the oversampling method. Behavior Research Methods, 46, 786-797.

https://doi.org/10.3758/s13428-013-0402-6

Israel, B. A., Eng, E., Schulz, A. J., \& Parker, E. A. (Eds.) (2013). Methods for community-based participatory research for health $\left(2^{\text {nd }}\right.$ ed.). San Francisco, CA: Wiley.

Jason, L., \& Glenwick, D. (Eds.). (2016). Handbook of methodological approaches to community-based research: Qualitative, quantitative, and mixed methods. New York, NY: Oxford University Press. https://doi.org/10.1093/med:psych/9780190243654.001.0001

Jones, K. P., Arena, D. F., Nittrouer, C. L., Alonso, N. M., \& Lindsey, A. P. (2017). Subtle discrimination in the workplace: A vicious cycle. Industrial and Organizational Psychology, 10(1), 51-76.

https://doi.org/10.1017/iop.2016.91

Kalton, G. (2009). Methods for oversampling rare subpopulations in social surveys. Survey Methodology, $35(2), 125-141$.

Levy, P. S., \& Lemeshow, S. (2013). Sampling of populations: Methods and applications $\left(4^{\text {th }}\right.$ ed.). New York, NY: Wiley. https://doi.org/10.1002/9780470374597

Lui, P. P., \& Quezada, L. (2019). Associations between microaggression and adjustment outcomes: A metaanalytic and narrative review. Psychological Bulletin, 145(1), 45-78. http://dx.doi.org/10.1037/bul0000172

Nielsen, M., Haun, D., Kärtner, J., \& Legare, C. H. (2017). The persistent sampling bias in developmental psychology: A call to action. Journal of Experimental Child Psychology, 162, 31-38.

http://dx.doi.org/10.1016/j.jecp.2017.04.017

Noble, S. U. (2018). Algorithms of oppression: How search engines reinforce racism. New York, NY: NYU Press. https://doi.org/10.2307/j.cttlpwt9w5

O'Neil, C. (2017). Weapons of math destruction: How big data increases inequality and threatens democracy. New York, NY: Broadway Books.

Onwuegbuzie, A. J., \& Collins, K. M. (2007). A typology of mixed methods sampling designs in social science research. Qualitative Report, 12(2), 281-316.

Ozanne, J. L., Davis, B., Murray, J. B., Grier, S., Benmecheddal, A., Downey, H., \& ... Veer, E. (2017). Assessing the societal impact of research: The relational engagement approach. Journal of Public Policy and Marketing, 36(1), 1-14. https://doi.org/10.1509/jppm.14.121 
Palinkas, L. A., Horwitz, S. M., Green, C. A., Wisdom, J. O., Duan, N., \& Hoagwood, K. (2015). Purposeful sampling for qualitative data collection and analysis in mixed method implementation research.

Administration and Policy in Mental Health and Mental Health Services Research, 42(5), 533-544.

https://doi.org/10.1007/s10488-013-0528-y

Patton, M. Q. (2015). Qualitative research \& evaluation methods: Integrating theory and practice (4th ed.). Thousand Oaks, CA: Sage.

Perez, C. C. (2019). Invisible women: Exposing data bias in a world designed for men. New York, NY: Abrams Press.

Robinson, S. L., O'Reilly, J., \& Wang, W. (2013). Invisible at work: An integrated model of workplace ostracism. Journal of Management, 39(1) 203-231. https://doi.org/10.1177/0149206312466141

Rocchi, M., Beaudry, S. G., Anderson, C., \& Pelletier, L. G. (2016). The perspective of undergraduate research participant pool nonparticipants. Teaching of Psychology, 43(4), 285-293.

https://doi.org/10.1177/0098628316662756

Rodrìguez, Y., \& Gaviria, J. (2019). Ergonomic analysis of working conditions of a recycler community in Medellìn, Colombia. In In R. D. Roscoe, E. K. Chiou, \& A. R. Wooldridge (Eds.), Advancing diversity, inclusion, and social justice through human systems engineering (pp. 135-150). Boca Raton, FL: CRC Press. https://doi.org/10.1080/00140139.2020.1818431

Rogers, C., Valdez, R. S., Gilbert, J.E., Lange Morales, K., Rogers, W., Thatcher, A., and \& Wooldridge, A. R. (2020, December). Scaling out impact: Emerging human factors applications addressing society challenges. Proceedings of the Human Factors and Ergonomics Society, 64(1), 863-867.

https://doi.org/10.1177/1071181320641200/

Roscoe, R. D., Acemyan, C. Z., Jacobs, K., Robertson, M. M., Yoo, A., \& Mitchell, D. (2020, December). Media and public engagement for societal impact: Getting the word out about human factors and ergonomics. Proceedings of the Human Factors and Ergonomics Society, 64(1), 555-558.

https://doi.org/10.1177/1071181320641126

Roscoe, R. D., Becker, D. V., Branaghan, R. J., Chiou, E. K., Gray, R., Craig, S. D., Gutzwiller, R. S., \& Cooke, N. J. (2019). Bridging psychology and engineering to make technology work for people. American Psychologist, 74(3), 394-406. https://doi.org/10.1037/amp0000444

Roscoe, R. D., Chiou, E. K., \& Wooldridge, A. R. (Eds.) (2020). Advancing diversity, inclusion, and social justice through human systems engineering. Boca Raton, FL: CRC Press.

https://doi.org/10.1201/9780429425905

Salazar, M. R., Feitosa, J., \& Salas, E. (2017). Diversity and team creativity: Exploring underlying mechanisms. Group Dynamics: Theory, Research, and Practice, 21(4), 187-206.

https://doi.org/10.1037/gdn0000073

Salazar, M. R., Lant, T. K., Fiore, S. M., \& Salas, E. (2012). Facilitating innovation in diverse science teams through integrative capacity. Small Group Research, 43(5), 527-558.

https://doi.org/10.1177/1046496412453622 
Schmitt, M. T., Branscombe, N. R., Postmes, T., \& Garcia, A. (2014). The consequences of perceived discrimination for psychological well-being: A meta-analytic review. Psychological Bulletin, 140(4), 921948. https://doi.org/10.1037/a0035754

Shadish, W. R., Cook, T. D., \& Campbell, D. T. (2002). Experimental and quasi-experimental designs for generalized causal inference. Boston, MA: Houghton Mifflin.

Sheridan, R., Martin-Kerry, J., Hudson, J., Parker, A., Bower, P., \& Knapp, P. (2020). Why do patients take part in research? An overview of systematic reviews of psychosocial barriers and facilitators. Trials, 21(1), 1-18. https://doi.org/10.1186/s13063-020-4197-3

Slemp, G. R., Kern, M. L., Patrick, K. J., \& Ryan, R. M. (2018). Leader autonomy support in the workplace: A meta-analytic review. Motivation and Emotion, 42, 706-724. https://doi.org/10.1007/s11031-018-9698-y

Stonewall, J., Dorneich, M. C., Shenk, L., Krejci, C. C., \& Passe, U. (2019). Inclusive decision-making: Applying human factors methods to capture the needs and voices of marginalized populations. In R. D. Roscoe, E. K. Chiou, \& A. R. Wooldridge (Eds.), Advancing diversity, inclusion, and social justice through human systems engineering (pp. 11-30). Boca Raton, FL: CRC Press.

https://doi.org/10.1080/00140139.2020.1818431

Valdez, R. S., \& Holden, R. J. (Eds.) (2021). The patient factor: Applications of patient ergonomics. Boca Raton, FL: CRC Press. https://doi.org/10.1201/9780429293009

Valerio, N. A., Rodriguez, N., Winkler, P., Lopez, J., Dennison, N., Liang, Y., \& Turner, B. J. (2016). Comparing two sampling methods to engage hard-to-reach communities in research priority setting. $B M C$ Medical Research Methodology, 16, Article 146. https://doi.org/10.1186/s12874-016-0242-z

Van den Broeck, A., Ferris, D. L., Chang, C., \& Rosen, C. C. (2016). A review of Self-Determination Theory's basic psychological needs at work. Journal of Management, 42(5), 1195-1129.

https://doi.org/10.1177/0149206316632058

Wachter-Boettcher, S. (2017). Technically wrong: Sexist apps, biased algorithms, and other threats of toxic tech. New York, NY: W. W. Norton \& Company.

Waheed, W., Hughes-Morley, A., Woodham, A., Allen, G., \& Bower, P. (2015). Overcoming barriers to recruiting ethnic minorities to mental health research: a typology of recruitment strategies. $B M C$ Psychiatry, 15(1), Article 101. https://doi.org/10.1186/s12888-015-0484-z

Walker, R. (2020). The opportunity cost of compulsory research participation: Why psychology departments should abolish involuntary participant pools. Science and Engineering Ethics, 26, 2835-2847.

https://doi.org/10.1007/s11948-020-00232-2

Wallerstein, N., \& Duran, B. (2010). Community-based participatory research contributions to intervention research: The intersection of science and practice to improve health equity. American Journal of Public Health, 100 (S1), S40-S46. https://doi.org/10.2105/AJPH.2009.184036

Wallerstein, N., Duran, B., Oetzel, J. G. \& Minkler, M. (Eds.) (2018). Community-based participatory research for health: Advancing social and health equity ( $3^{\text {rd }}$ ed.). San Francisco, CA: Jossey-Bass.

Wesley, D. B., Boxley, C., Kurgatt, S., King, C. J., \& Miller, K. E. (2019). The intersection of human factors engineering and health equity. In R. D. Roscoe, E. K. Chiou, \& A. R. Wooldridge (Eds.), Advancing 
diversity, inclusion, and social justice through human systems engineering (pp. 63-78). Boca Raton, FL: CRC Press. https://doi.org/10.1080/00140139.2020.1818431

Williams, R. M., \& Gilbert, J. E. (2019). "Nothing about us without us": Transforming participatory research and ethics in human systems engineering. In R. D. Roscoe, E. K. Chiou, \& A. R. Wooldridge (Eds.), Advancing diversity, inclusion, and social justice through human systems engineering (pp. 113-134). Boca Raton, FL: CRC Press. https://doi.org/10.1080/00140139.2020.1818431

Wood, L. (2017). The ethical implications of community-based research: A call to rethink current review board requirements. International Journal of Qualitative Methods, 16, 1-7.

https://doi.org/10.1177/1609406917748276

Zhang, Q., Goodman, M., Adams, N., Corneil, T., Hashemi, L., \& ... Coleman, E. (2020). Epidemiological considerations in transgender health: A systematic review with focus on higher quality data. International Journal of Transgender Health, 21(2), 125-137. https://doi.org/10.1080/26895269.2020.1753136

\section{Acknowledgments}

This paper was prepared based on the author's remarks in a panel discussion at the 2020 Human Factors and Ergonomics Society annual meeting. The panel, titled "Designing for Diversity: Implications for Research and Practice," also included panelists Dr. Abigail R. Wooldridge, Dr. Shannon C. Roberts, and Dr. Rupa S. Valdez.. The current paper was supported in part by the United States National Science Foundation (NSF \#1712328). Opinions, findings, conclusions, or recommendations expressed in this work are those of the author and do not necessarily reflect the reviews of NSF. The author is grateful for the insights of numerous colleagues in $\mathrm{HF} / \mathrm{E}$ and particularly those working in healthcare and health equity. 